\title{
Wind tunnel experimentation on stationary downbursts at WindEEE Dome
}

\author{
Massimiliano Burlando", Djordje Romanić ${ }^{2}$, Horia Hangan' and Giovanni \\ Solari \\ Department of Civil, Chemical and Environmental Engineering (DICCA), University of Genoa \\ Via Montallegro 1, 16145, Genova (Italy) \\ massimiliano.burlando@unige.it ; giovanni.solari@unige.it \\ Wind Engineering, Energy and Environment (WindEEE) Research Institute, Western \\ University \\ 2535 Advanced Avenue, London (Ontario, Canada, N6M 0E2) \\ dromanic@uwo.ca; hmhangan@uwo.ca
}

\begin{abstract}
In the context of the European Project THUNDERR a scientific collaboration between the Wind Engineering and Structural Dynamics (Windyn) Research Group of the University of Genoa (Italy) and the Wind Engineering, Energy and Environment (WindEEE) Research Institute of Western University (Canada) has been established to study experimentally at the WindEEE Dome facility how the main geometrical and mechanical properties of downbursts are affected by different cloud base outflows of stationary thunderstorms. At present, the analysis of the downbursts simulated experimentally is ongoing and some preliminary elaborations have been obtained concerning the qualitative and quantitative interpretation of the corresponding signals. Classical signal decomposition was applied to experimentally produced downbursts in the WindEEE Dome in order to study transient features of the time series. This study presents the results for two radial positions from downdraft centre and for twenty repetitions per radial position. Several prospects for further research are also discussed.
\end{abstract}

Keywords: Downbursts $\cdot$ THUNDERR project $\cdot$ WindEEE Dome $\cdot$ Signal analysis · Extreme winds $\cdot$ Impinging jets

\section{$1 \quad$ Introduction}

Downbursts are vigorous winds that descend from a thunderstorm and spread out rapidly once they encounter the ground. Strong downbursts can cause damage similar to that of an EF0 (105-38 $\left.\mathrm{m} \mathrm{s}^{-1}\right)$ or EF1 (38-49 $\left.\mathrm{m} \mathrm{s}^{-1}\right)$ tornados (McDonald et al., 2006). However, the dynamics of downbursts and tornadoes are completely different. In the initial stages of thunderstorm, a powerful updraft is the main feature of the cloud dynamics. The updraft is responsible for the influx of warm and moist air that "feeds" 
the thunderstorm. In this stage, the cumuliform cloud is typically a cumulus congestus, which will later evolve into a cumulonimbus. That is, as the growth of raindrops and hailstones continues in the mature cloud, eventually their weight is larger than the uplift caused by the updraft and they start falling to the ground. As the hydrometeors fall towards the ground two processes take place: (1) their evaporation and melting in the subsaturated environment underneath the cloud, and (2) the drag on the ambient air caused by the falling hydrometeors, as described by the Stokes' law. In many cases, an inflow of dry air in the rear flank of the storm additionally amplifies evaporation and melting. The latent heat of evaporation/melting which is extracted from the surrounding air results in the cooling of the air in the precipitation region of thunderstorm, thus creating a downdraft of cold air that impinges on the surface. The downdraft and its radial spread upon hitting the ground are known as downburst. Meteorological aspects of downbursts and their evolution were studied in the pioneering studies by Simpson (1969), Charba (1974), Fujita (1981), Wakimoto (1982), Droegemeier and Wilhelmson (1987), and Sherman (1987), among many others.

In 2017, a first set of experiments has been carried out at WindEEE Dome (Hangan at al., 2017) to study the class of downbursts induced by stationary thunderstorm outflows (Solari et al., 2018). This class of phenomena comprehends all thunderstorms that are stationary in meteorological terms, which means that their vertical axis does not move with respect to the ground. However, even with the approximation of stationary thunderstorm, the resulting flow field is unsteady as it changes according to the time evolution of the cumulonimbus cloud as it passes from mature to dissipative stages.

In accordance with the above simplified assumption of real thunderstorms, the experiments presented in this paper were carried out in 2017 at WindEEE Dome and the focus was mainly on the simulation of downbursts generated by stationary but unsteady thunderstorm outflows. The main objective of this paper is to subject the measured time series to the classical signal decomposition techniques for transient winds (e.g., Holmes et al., 2008; Solari et al., 2015; Burlando et al., 2017). Although these statistical techniques were applied to a number of full scale downburst events, it will be interesting to investigate their applicability to laboratory produced downbursts. Moreover, each downburst experiment in WindEEE Dome was repeated twenty times in order to build high statistical significance of the obtained results, as well as to account for the random nature of turbulent flow and its high dependency on initial conditions.

Downburst outflows produced in WindEEE Dome are effectively large impinging jets of various diameters. Over the last several decades, the impinging jet approach to simulate downburst has been established as a recognized laboratory technique to replicate full scale events, in particular for wind engineering purposes. Wood et al., (2001) used continues impinging jet to study downburst outflows over different topographies as well as flat surface. Two goals of their study were the investigation of the evolution of velocity profile at different radial distances from downburst centre and the comparison of speed-up factors between downbursts and atmospheric boundary layer (ABL) winds. Chay and Letchford (2002) and Letchford and Chay (2002) investigated the surface pressure distribution on a cube immersed in stationary and moving 
downbursts, respectively. Similar to Wood et al. (2001), their goal was also to compare the pressure distribution of stationary and translating downbursts to the one produced by ABL winds. For instance, they concluded that at lower translation speeds, translating downbursts can accurately be approximated as a stationary downburst. They also reported the largest similarity in pressure distributions between the uniform ABL winds and a stationary downburst at the radial distance $R / D=1$, where $R$ is the radial distance from downburst centre and $D=0.51 \mathrm{~m}$ is the jet diameter in their simulator. At a geometric scale of 1:3000, Mason et al., (2005) used pulsed impinging jet to simulate stationary downburst through flow visualization, velocity measurements, and surface pressures. Their jet was the same as the one used by Chay and Letchford (2002) and Letchford and Chay (2002). Xu and Hangan (2008) focused their analysis on dependencies of impinging jets on Reynolds number (i.e., scale), boundary conditions (geometry and surface roughness) and inlet conditions. They found that below the critical Reynolds number, the boundary layer height formed on the surface decreases while the maximum velocity increases by increasing the Reynolds number. Moreover, it was demonstrated that the flow is weakly dependent on the distance between the jet outlet and the surface for distances larger than the ring vortex formation length. However, their jet diameter was only $D=0.0381 \mathrm{~m}$. McConville et al (2009) investigated the transient nature of downbursts by directly controlling the simulator fans, as well as by using two different opening of the simulator. Their experiments were repeated ten times and the ensemble average was used for subsequent analyses. The jet diameter in their experiments was $D=1 \mathrm{~m}$. It should be pointed out that they aligned the velocity signals from ten repetitions by assuming the time to be zero when the velocity in the ramp-up segment of time series is $40 \%$ of the peak velocity. At the end, it should be noted that the diameter of impinging jets analysed in the present paper is $D=3.2 \mathrm{~m}$, which is by an order of magnitude or so larger than in all previous studies.

In the following, a short description of the experimental settings used to simulate downbursts at WindEEE Dome is reported in section 2. An overview of decomposition methodology is provided in section 3. The measured time series in WindEEE Dome and their analyses are discussed in details in section 4. Lastly, the paper is closed with conclusions and prospects for further research in section 5.

\section{Experimental settings}

The Wind Engineering, Energy and Environment (WindEEE) Dome at Western University in Canada is a hexagonal wind tunnel with an inner diameter of about $25 \mathrm{~m}$, designed to reproduce, at large scale and under controlled inflow and boundary conditions, time-dependent swirling winds such as tornadoes, downbursts, and gust fronts (Hangan et al, 2017). A schematics of the WindEEE Dome cross-section is depicted in Fig. 1. The total of one-hundred fans are distributed along the perimeter of the test chamber with one wall being equipped with sixty fans (so-called 60-fan wall). The 60fan wall can also be used to produce ABL winds (Hangan et al, 2017). In addition six 
larger fans are installed in the upper plenum of the WindEEE Dome in order to produce either tornadoes or downbursts. The upper plenum is connected to the test chamber by a bell mouth with mechanical louvers that can be controlled remotely. The height of the chamber $(H)$ is $3.75 \mathrm{~m}$ and the bell mouth opening used to generate downburst in this study is $D=3.2 \mathrm{~m}$; thus $D \sim H$.

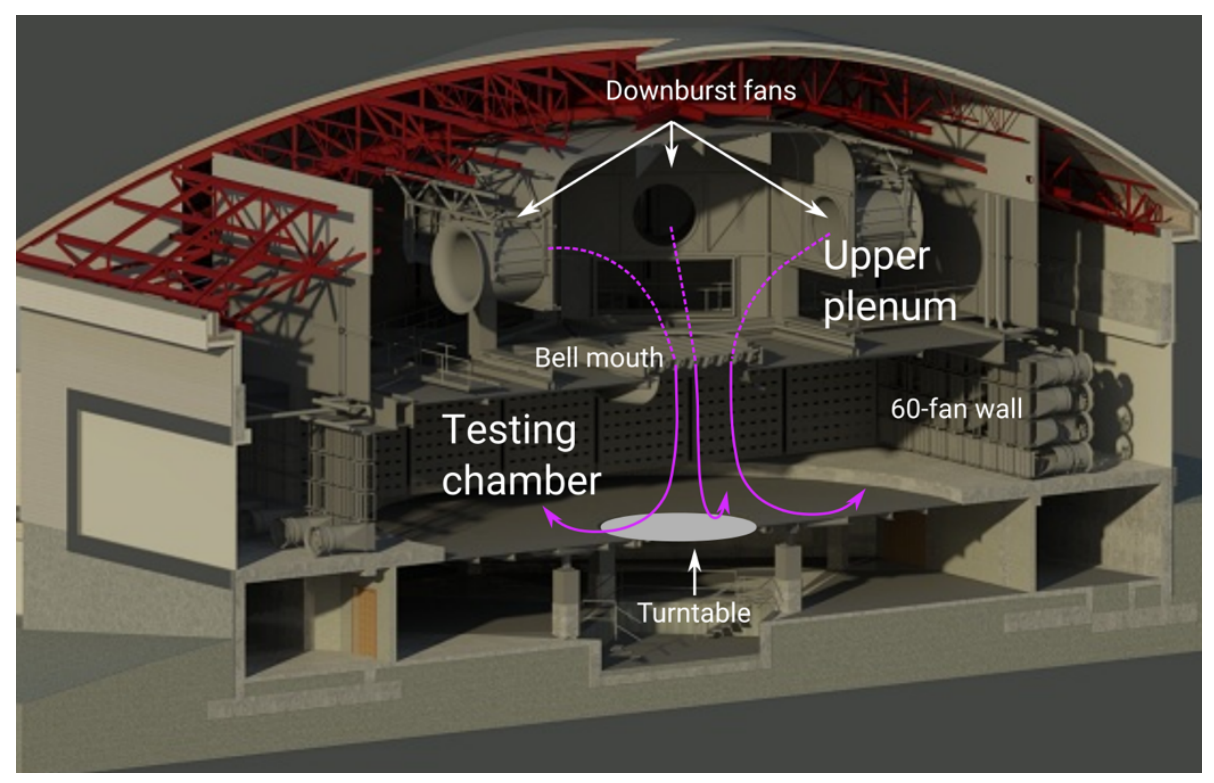

Fig. 1 Schematics of WindEEE Dome and downburst flow

In terms of experimental inflow conditions, downbursts are generated producing a dynamic (sudden) vertical flow downward from the bell mouth mounted at the ceiling of the test chamber (Fig. 1). Since this study is interested in stationary downburst, the position of the bell mouth installed on a guillotine is kept fixed. However, using various translation speeds of the guillotine, WindEEE Dome is capable of producing translating downbursts. In order to simulate as close as possible the transient nature of real downbursts, the time of louvres to open and close was approximately $10 \mathrm{~s}$. Jet velocity at the exit of the bell mouth (i.e. outlet velocity) of $V_{j e t} \approx 9 \mathrm{~m} \mathrm{~s}^{-1}$ is approximately $20 \%$ of the maximum rotation per minute (RPM) of the upper six fans in the WindEEE Dome.

The experiment setup is portrayed in Fig. 2. The data presented in this paper are obtained at two radial positions from downdraft centre, i.e., $R / D=1$ and $R / D=2$. In both cases, measurements were taken at $0.1 \mathrm{~m}$ above the surface. Velocity measurements are conducted deploying a Cobra Probe (Turbulent Flow Instrumentation, 2015) with the sampling frequency of $f_{s}=2500 \mathrm{~Hz}$. The simulated downbursts impinged on the bare floor which was not populated with any surface roughness elements or topography features. For each $R / D$ position, experiments are repeated twenty times. 
This study investigates individual time series as well as their ensemble average, defined as:

$$
\left\langle V\left(t_{j}\right)\right\rangle=\frac{1}{M} \sum_{i=1}^{M} V^{(i)}\left(t_{j}\right) .
$$

Here, $\left\langle V\left(t_{j}\right)\right\rangle$ is the ensemble-average of the $j$ th wind speed $(V)$ record in the time series $(j=1,2, \ldots, N), N$ is the total number of records in the time series, and $i=$ $1,2, \ldots, M$ is the $i$ th member of the ensemble $(M=20)$, and $t$ is the time.

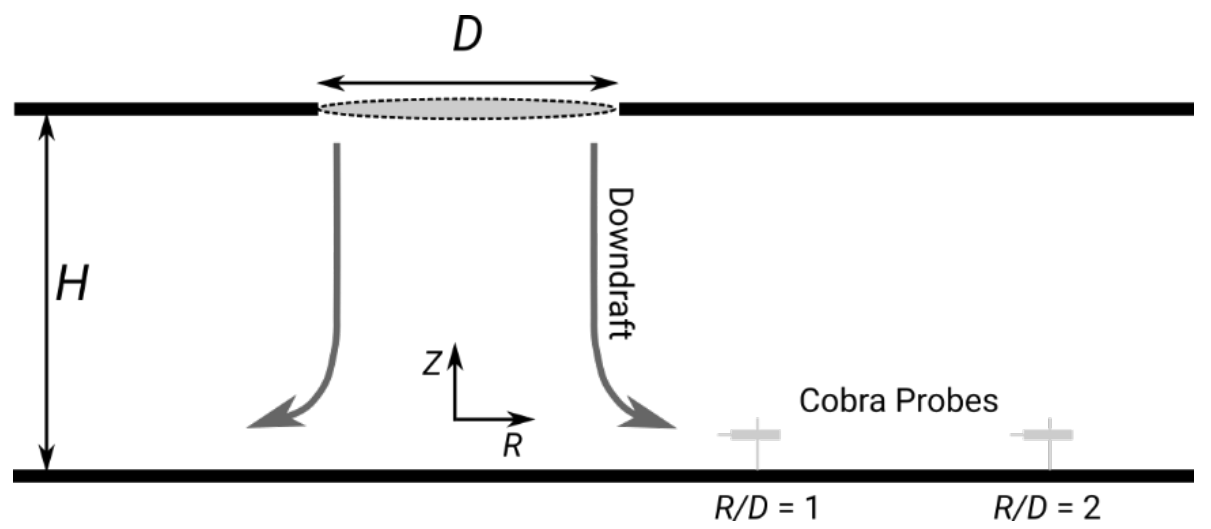

Fig. 2 Experiment setup

\section{Brief overview of signal analysis methodology}

The extension of Reynolds decomposition to transient wind velocity time series is applied to analyse experimentally produced downbursts in this study (e.g., Holmes et al., 2008; Kwon and Kareem 2009; Solari et al., 2015; Burlando et al., 2017):

$$
V(t)=\bar{V}(t)+V^{\prime}(t)
$$

where $t \in[0, \Delta T]$ is the time, , $\Delta T$ is the period for which the velocity signals are examined, $\bar{V}(t)$ is the slowly-varying mean wind velocity (associated with low-frequency content) and $V^{\prime}(t)$ is the residual fluctuation (associated with the high-frequency content of $V$ ).

By expressing the residual fluctuations as:

$$
V^{\prime}(t)=\sigma_{V}(t) \tilde{V}^{\prime}(t),
$$

where $\tilde{V}^{\prime}(t)$ is the so-called reduced turbulent fluctuation, Eq. (2) can be cast in the following form:

$$
V(t)=\bar{V}(t)\left(1+I_{V}(t) \tilde{V}^{\prime}(t)\right),
$$


where $\sigma_{V}(t)$ is the slowly-varying standard deviation of $V^{\prime}$, and $I_{V}(t)=\sigma_{V}(t) / \bar{V}(t)$ is therefore the slowly-varying turbulence intensity. The analyzed features of the experimentally produced downbursts in WindEEE Dome are $V(t), \bar{V}(t), I_{V}(t)$, and $\tilde{V}^{\prime}(t)$.

\section{Results and discussion}

Fig. 3 shows the instantaneous wind speed time series measured at $R / D=1$ (left) and 2 (right). As pointed out earlier, the experiment has been repeated 20 times in order to capture the variability of this transient phenomenon. The black line corresponds to the ensemble mean of all repetitions.

Both the mean time series (black lines), which correspond to the deterministic part of this phenomenon, as well as the statistical repeatability of the simulations show that the signal associated with downbursts consists of three main parts: (1) a sudden rampup followed by a rapid decrease of the wind speed, which determines the first maximum of the signal; (2) a plateau that can be more or less pronounced depending on the distance from the downburst centre; and (3) a tail during the downburst dissipation stage. Qualitatively, these two time series show the same transient footprint as the velocity records of full scale events (e.g., Sherman, 1987; Holmes et al., 2008; De Gaetano et al., 2014; Burlando et al., 2017).
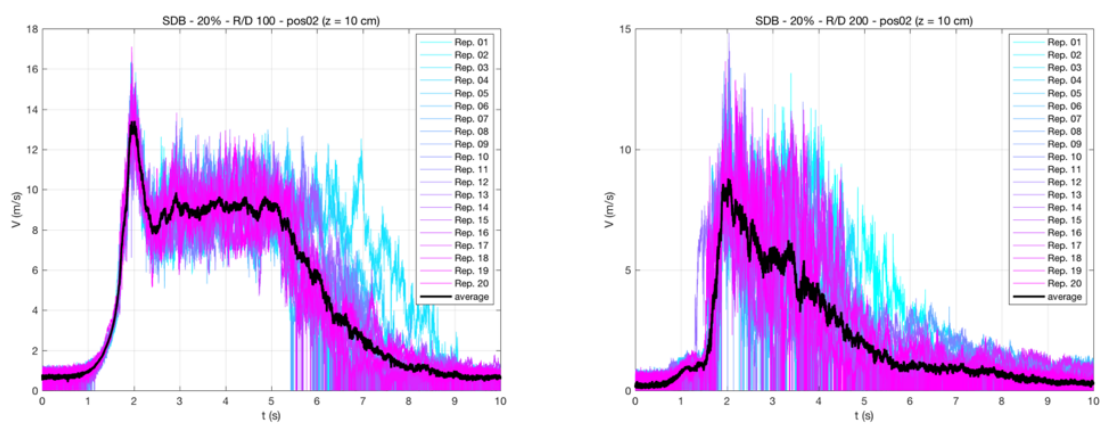

Fig. 3 Time series of the wind speed measured at $R / D=1$ (left) and at $R / D=2$ (right) and their ensemble mean.

In the following, the wind velocity decomposition described in Section 3 is reported. Fig. 4 shows the slowly-varying mean wind velocity, $\bar{V}(t)$, obtained using a running mean with moving average period of 30 seconds, chosen according to Solari et al. (2015).

Fig. 5 shows the slowly-varying standard deviation, $\sigma_{V}(t)$, of the residual fluctuations. The turbulent fluctuations increase suddenly at the beginning of the downburst ramp-up, which is at about $1.5 \mathrm{~s}$, then remain almost constant until the end of the 
aforementioned plateau, which lasts approximately up to $5 \mathrm{~s}$ and $3.5 \mathrm{~s}$ at $R / D=1$ and $R / D=2$, respectively. Fluctuations increase moving radially further from the downdraft, i.e. from around $0.7 \mathrm{~m} \mathrm{~s}^{-}$at $R / D=1$ to around $1.2 \mathrm{~m} \mathrm{~s}^{\wedge}$ at $R / D=2$, while at the same time the wind speed decreases. Consequently, this leads to an increase of turbulence intensity from about 0.1 to 0.2 at $R / D=1$ and $R / D=2$, respectively. Note that these values of $I_{V}$ are comparable to the ones that are commonly found in the ABL (see for instance Pagnini et al., 2015).
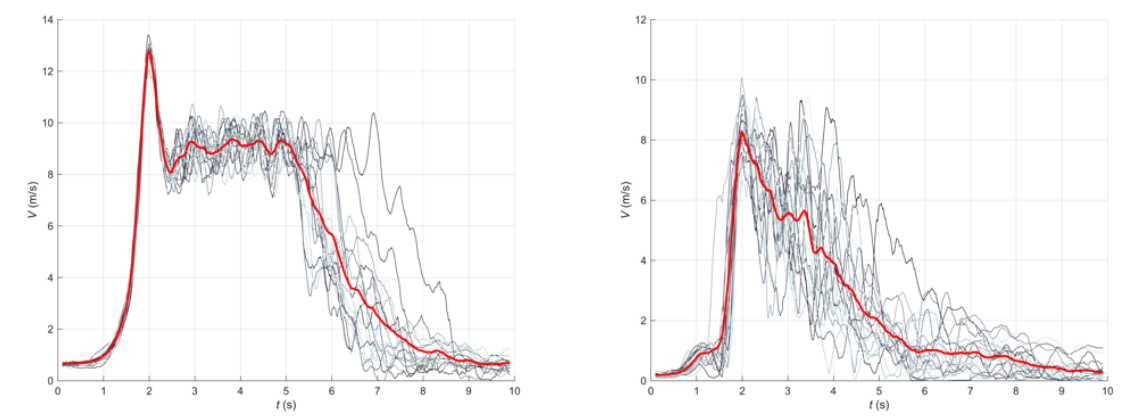

Fig. 4 Time series of the running mean of the wind speed measured at $R / D=1$ (left) and at $R / D=2$ (right), averaged over a period of $30 \mathrm{~s}$. Red lines represent the ensemble mean over all the black lines.
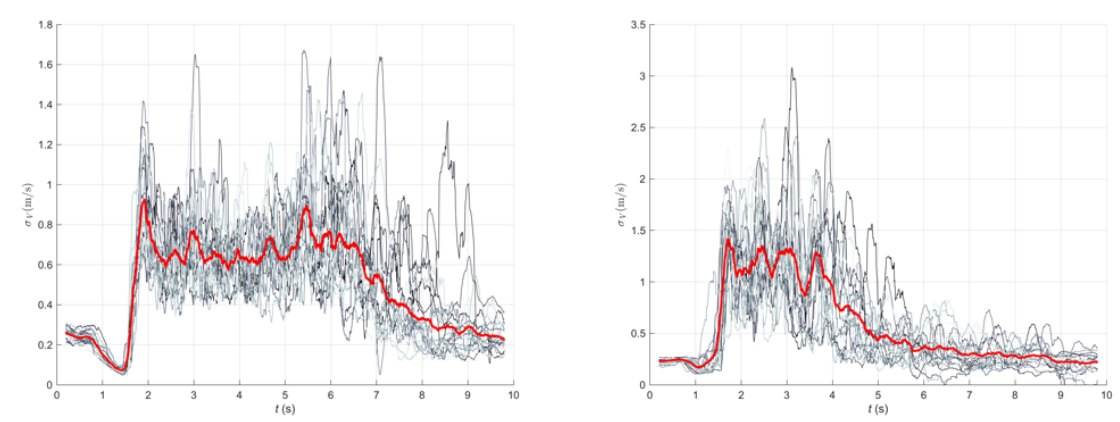

Fig. 5 Time series of the time-dependent standard deviations at $R / D=1$ (left) and at $R / D=2$ (right), considering a period of $30 \mathrm{~s}$. Red lines represent the ensemble mean over all the black lines.

Fig. 6 shows the reduced turbulent fluctuations, $\tilde{V}^{\prime}(t)$. This parameter is usually dealt with as a rapidly-varying stationary Gaussian random process with zero mean and unit standard deviation (Chen and Letchford, 2004). This approach is widely shared in literature, as reported for instance by Solari et al. (2015) and Zhang et al. (2017) and it holds also for the 20 replications analysed one by one through a global analysis. However, if the ensemble mean of $\tilde{V}^{\prime}(t)$ is considered (i.e. red lines in Fig. 6), it seems that 
the assumption of statistical stationarity and in particular randomness of these signals does not hold, especially for the signal corresponding to $R / D=1$ comparing the period during the ramp-up (1.5-2.5 s) and partly the plateau (up to $5 \mathrm{~s}$ ) with respect to the rest. Closer inspection of Fig. 6 shows that this departure from Gaussian process is actually true for all the 20 replications, even though this behaviour is partially hidden by noise.
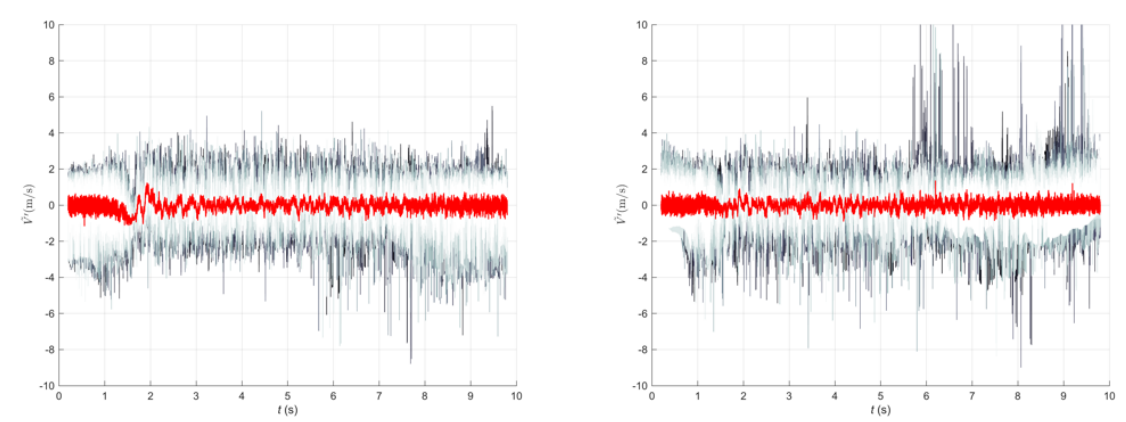

Fig. 6 Time series of reduced turbulent fluctuations at $R / D=1$ (left) and at $R / D=2$ (right). Red lines represent the ensemble mean over all the black lines.

\section{Perspectives}

This paper presented the first results of systematic analysis of the downburst time series measured in the WindEEE Dome. The results are shown for two radial distances from downdraft centre; namely $R / D=1$ and $R / D=2(R$ is the radial position and $D$ is the diameter of the downdraft) and one height above surface $(Z=0.1 \mathrm{~m})$. However, twenty repetitions of tests for each $R / D$ are performed in order to analyse the transient nature of the phenomena. The analysis encompass the investigations of individual time series and their ensemble average. Using the signal analysis technique, all time series are decomposed into slowly-varying mean, slowly-varying turbulence intensity, and reduced turbulent fluctuations.

There are two great advantages of simulating experimentally-produced downbursts in a wind tunnel: firstly, the phenomenon can be generated under strongly controlled conditions; secondly, it can be replicated many times with exactly the same boundary conditions and forcing. This allows, on the one hand, to avoid any kind of environmental disturb, like background flows, which cannot be easily recognised and removed in real field measurements and, on the other hand, to distinguish deterministic and random parts of signals.

The downburst simulated at WindEEE was a transient stationary phenomenon without background flow. The lack of background flow allowed to analyse the deterministic part of the downburst, i.e. the ensemble mean $\langle V(t)\rangle$, without any external interference 
and to distinguish three phases of its evolution: ramp-up, plateau, and dissipation. Besides, the analysis pointed out that the randomness superimposed onto the deterministic part of the signal could be statistically non-stationary especially in the period of ramp-up and immediately afterwards. This is not confirmed by field measurements, however, in which the statistical characteristics of the reduced turbulence apparently do not change by time. During a real downburst event, the turbulence field obtained from direct measurements is almost never completely free from interactions with the boundary layer flow and its reduced turbulence is surely affected by the mixing with the background flow, which makes more difficult to compare experiments with field data.

By the end of 2018 a set of new experiments will be performed at WindEEE Dome in order to study more complex, but also more realistic, meteorological conditions associated with real downbursts, such as the case of background flows superimposed to thunderstorm outflows and translating downbursts.

Acknowledgements This research is funded by European Research Council (ERC) under the European Union's Horizon 2020 research and innovation program (grant agreement No. 741273) for the project THUNDERR - Detection, simulation, modelling and loading of thunderstorm outflows to design wind-safer and cost-efficient structures - through an Advanced Grant (AdG) 2016 and by "Compagnia di San Paolo" for the "Wind monitoring, simulation and forecasting for the smart management and safety of port, urban and territorial systems" Project (grant number 2015.0333, ID ROL: 9820).

\section{References}

Burlando, M., De Cio, A., Pizzo, M., and Solari, G. (2017). Analysis of Wind Vertical Profiles of Thunderstorm Events in the Mediterranean. 9th Asian-Pacific Conference on Wind Engineering, Dec. 3-7, Auckland, New Zealand.

Burlando, M., Romanić, D., Solari, G., Hangan, H., and Zhang, S. (2017) Field Data Analysis and Weather Scenario of a Downburst Event in Livorno, Italy, on 1 October 2012. Monthly Weather Review 145, 3507-3527.

Chay, M., and Letchford, C. (2002). Pressure Distributions on a Cube in a Simulated Thunderstorm Downburst-Part A: Stationary Downburst Observations. Journal of Wind Engineering and Industrial Aerodynamics 90, 711-732.

Charba, J. (1974). Application of Gravity Current Model to Analysis of Squall-Line Gust Front. Monthly Weather Review 102, 140-156.

De Gaetano, P., Repetto, M. P., Repetto, T., and Solari, G. (2014). Separation and Classification of Extreme Wind Events from Anemometric Records. Journal of Wind Engineering and Industrial Aerodynamics 126, 132-143. 
Droegemeier, K. K., and Wilhelmson, R. B. (1987). Numerical Simulation of Thunderstorm Outflow Dynamics. Part I: Outflow Sensitivity Experiments and Turbulence Dynamics. Journal of the Atmospheric Sciences 44, 1180-1210.

Fujita, T.T. (1981). Tornadoes and Downbursts in the Context of Generalized Planetary Scales. Journal of the Atmospheric Sciences 38, 1551-1534.

Hangan, H., Refan M., Jubayer, C., Romanic, D., Parvu D., LoTufo, J., and Costache, A. (2017). Novel Techniques in Wind Engineering, Journal of Wind Engineering and Industrial Aerodynamics $171,12-33$.

Holmes, J. D., Hangan, H. M., Schroeder, J. L., Letchford, C. W., and Orwig, K. D. (2008). A Forensic Study of the Lubbock-Reese Downdraft of 2002. Wind and Structures 11, 137152.

Kwon, D., and Kareem, A. (2009) Gust-Front Factor: New Framework for Wind Load Effects on Structures. Journal of Structural Engineering 135, 717-732.

Letchford, C.W., and Chay, M.T. (2002). Pressure Distributions on a Cube in a Simulated Thunderstorm Downburst. Part B: Moving Downburst Observations. Journal of Wind Engineering and Industrial Aerodynamics 90, 733-753.

Mason, M. S., Letchford, C. W., James, D. L. (2005). Pulsed Wall Jet Simulation of a Stationary Thunderstorm Downburst, Part A: Physical Structure and Flow Field Characterization. Journal of Wind Engineering and Industrial Aerodynamics 93, 557-580.

McConville, A. C., Sterling, M., and Baker, C. J. (2009). The Physical Simulation of Thunderstorm Downbursts Using an Impinging Jet. Wind and Structures 12, 133-149.

McDonald, J.R., Mehta, K. S., and Mani, S. (2006). A Recommendation for an Enhanced Fujita Scale (EF-Scale). Wind Science and Engineering Center, Texas Tech University, Lubbock, TX, US.

Pagnini, L.C., Burlando, M., and Repetto, M.P. (2015). Experimental power curve of small-size wind turbines in turbulent urban environment. Applied Energy 154, 112-121.

ISherman, D. J. (1987). The passage of a weak thunderstorm downburst over an instrumented tower. Monthly Weather Review 115, 1193-1205.

Simpson, J. E. (1969). A Comparison between Laboratory and Atmospheric Density Currents. Quarterly Journal of the Royal Meteorological Society 95, 758-765.

Solari, G., De Gaetano, P., and Repetto, M. P. (2015). Thunderstorm Response Spectrum: Fundamentals and Case Study. Journal of Wind Engineering and Industrial Aerodynamics 143, 62-77.

Solari, G., Burlando, M., and Repetto, M. P. (2018). THUNDERR: an ERC Project for the "Detection, Simulation, Modelling and Loading of Thunderstorm Outflows to Design WindSafer and Cost-Efficient Structures". International Workshop on Wind-Related Disasters and Mitigation, Mar. 11-14, Sendai, Japan.

Turbulent Flow Instrumentation. (2015). Getting Started-Series 100 Cobra Probe. Turbulent Flow Instrume Pty Ltd. URL: https://www.turbulentflow.com.au/Downloads/Getting\%20Started\%20-\%20Cobra\%20Probe.pdf. Accessed: 18 May 2018.

Wakimoto, R. M. (1982). The Life Cycle of Thunderstorm Gust Fronts as Viewed with Doppler Radar and Rawinsonde Data. Monthly Weather Review 110, 1060-1082. 
Wood, G. S., Kwok, K. C., Motteram, N. A., and Fletcher D. F. (2001). Physical and Numerical Modelling of Thunderstorm Downbursts. Journal of Wind Engineering and Industrial Aerodynamics 89, 535-552.

Zhang, S., Solari, G., De Gaetano, P., Burlando, M., and Repetto, M. P. (2017). A refined analysis of thunderstorm outflow characteristics relevant to the wind loading of structures. Probabilistic Engineering Mechanics (in press). DOI: 10.1016/j.probengmech.2017.06.003 